\title{
Discurso e cultura na aula de língua materna: uma abordagem discursiva da textualidade
}

\author{
Luciana Cristina Ferreira Dias (DIAS, Luciana C. F. D.) \\ Professora Doutora da Universidade Estadual do Centro-Oeste (Guarapava, Paraná) \\ - UNICENTRO \\ diaslucian@yahoo.com
}

\begin{abstract}
Resumo
Considerando a problemática acerca da linguagem e da identidade nos estudos de perspectiva discursiva, de Pêcheux e de Orlandi, este artigo analisa representações construídas discursivamente sobre o Brasil, compreendendo os sentidos produzidos em práticas de leitura em língua materna. O presente estudo de caso foi baseado na Proposta Multidimensional-Discursiva, de Serrani, que considera a interdependência entre três componentes: o intercultural, língua e discurso e práticas verbais. Analisando um texto de Marilena Chauí, em sala de aula, foi possível observar que a cultura brasileira e a estrutura da língua podem ser trabalhadas de maneira integrada. Podemos concluir que a articulação do componente sociocultural ao língua-discurso nos fornece uma chance de compreender o funcionamento discursivo de textos sobre cultura.
\end{abstract}

Palavras-chave: análise do discurso, identidade brasileira, ensaios, cultura.

\begin{abstract}
Focusing on problems related to language and identity in discourse studies, of Pêcheux and of Orlandi, this article analyzes discourse-constructed representations on Brazil regarding the meanings that surface in mother tongue reading practices. The present case study was based on the Multidimensional-Discursive Proposal, of Serrani, which considers the interrelationship of three components: intercultural, language-discourse, and verbal practices. The analysis of a text by Marilena Chauí, in the classroom, yielded positive results, showing that the Brazilian culture and language structure can be worked in an integrated manner. By linking the sociocultural and language/discourse components, the teacher can help students understand the discursive functioning of texts about culture.
\end{abstract}

Keywords: discourse analysis; Brazilian identity, essays, culture. 


\section{Introdução}

Neste artigo, interessa-me propor uma abordagem da brasilidade ou da identidade nacional do Brasil, entendida aqui como um componente sociocultural a ser trabalhado em práticas letradas voltadas à formação de professores, no ensino superior. Sabendo da incidência e da relevância da cultura no ensino não somente de língua estrangeira, mas também de língua materna, este estudo pretende apresentar uma proposta de como o componente cultural de uma nação, de um povo, de uma dada cultura pode permitir ao professor trabalhar a língua ou temas culturais relacionados a questões identitárias.

Tal reflexão acerca da cultura brasileira a ser trabalhada no ensino de Língua Portuguesa como elemento prioritário e não meramente casual foi inspirada a partir das discussões propostas por Serrani $(2005,2006,2007)$ nas quais a autora afirma que, embora haja um consenso entre professores, pesquisadores e coordenadores em defender o componente sociocultural como relevante no ensino de línguas, na prática tal componente ocupa um lugar acessório em termos de grades curriculares. ${ }^{1}$

Considerando minha experiência como professora de Língua portuguesa, em um curso de Licenciatura em Letras, em uma instituição estadual, julgo válido levar em conta que o ensino da língua não pode estar limitado a uma análise descontextualizada de elementos formais ou estruturais da língua. Há necessidade de o professor proporcionar espaços de discussões sobre a cultura, a memória, a identidade, atreladas ao ensino de língua materna a fim de levar os futuros professores a planejarem atividades fundamentadas em uma abordagem integrada entre os componentes culturais e os de língua-discurso.

Neste sentido, vale citar Serrani (2007, p. 55) para quem é preciso tanto considerar a memória sociocultural ao se planejar e implementar a educação de línguas quanto pensar que a língua é matéria-prima da constituição identitária. Portanto, conforme a autora "para que a língua seja um bom instrumento é preciso considerá-la muito mais que um mero instrumento" (SERRANI, 2005, p. 29).

A meu ver, é chegada a hora de o futuro professor de língua materna pensar seu país, sua cultura, sua literatura de forma mais ampla. Dessa maneira, a cultura pode constituir um espaço no qual se possa romper com visões tão arraigadas na sociedade, na mídia, no estrangeiro, nas quais o Brasil é abordado de forma estereotipada, reduzida, cristalizada, exótica.

Assim sendo, o presente estudo pretende, com base na proposta multidimensional (STERN, 1993; SERRANI, 2005), sugerir uma abordagem discursiva da textualidade de um ensaio da autoria de Marilena Chaú́, tendo-se em vista o contexto universitário. Para tanto, estou levando em consideração a integração dos componentes cultural e língua-discurso, à luz dos princípios da análise do discurso de linha francesa e de uma visão processual e histórica de língua.

\section{Implementação da proposta multidimensional: língua e memória cultural brasileira}

\footnotetext{
${ }^{1}$ É válido destacar a contribuição de Serrani (2005) a partir de suas reflexões em torno do professor como "mediador cultural", ou seja, um docente "apto para realizar práticas de mediação sócio-cultural, contemplando o tratamento de conflitos identitários e contradições sociais, na linguagem da sala de aula" (SERRANI, 2005, p. 15).
} 
Considerando-se uma proposta multidimensional-discursiva, em termos de componentes estruturantes, trabalhar com o componente intercultural precisa fazer parte do planejamento de cursos ou aulas, uma vez que a cultura permite uma deflagração da relação linguagem e identidade, dentro do ensino da Língua Portuguesa. A relevância de tal abordagem reside no fato de que a proposta multidimensional coloca em cena questões discursivas na prática e permite que trabalhemos com seus conceitos, de maneira mais concreta.

Em termos de construção de um currículo, a concepção de currículo multidimensional define-se por oposição à de currículo unidimensional (STERN, 1993). Um planejamento elaborado sob a perspectiva de um currículo unidimensional segue somente uma progressão (no caso da língua portuguesa, por exemplo, pensa-se exclusivamente no ensino das regras ou da descrição lingüística ou ainda na abordagem de tópicos em produção textual). Um planejamento ancorado na perspectiva de um currículo multidimensional enfocará não apenas uma, mas várias dimensões relacionadas entre si.

Com efeito, levando-se em conta os processos sócio-históricos de produção de sentidos e os movimentos da identidade nacional na história, entender a cultura a partir de um exame diferenciado em uma perspectiva multidimensional e discursiva nos coloca diante de alguns desafios. Uma complementação multidimensional requer um olhar mais profundo sobre os conteúdos e sobre as práticas a serem desenvolvidas em sala de aula.

Neste sentido, é válido apresentar a formulação esquemática de uma estruturação curricular dentro de proposta multidimensional, apoiada em três componentes interrelacionados ${ }^{2}$ : (1) Intercultural (ênfase nas memórias socioculturais nacionais com foco na consideração da diversidade cultural); (2) Língua-Discurso e (3) de Práticas Verbais (SERRANI, 2005, p. 29-37).

(1) Componente intercultural: o fato de tal componente ser assim denominado pluricultural/intercultural se deve ao reconhecimento, ao desenvolvimento e à inclusão da pluralidade e da diversidade nos conteúdos como a condição básica para a compreensão da dimensão constitutivamente heterogênea de toda língua. Dessa forma, nas palavras de Serrani (2005), é preciso pensar em quais conteúdos de cultura estão sendo considerados em uma atividade. Vale dizer que este componente divide-se em três eixos temáticos, a saber:

(1.1) Territórios e espaços. Tomando como base que o aprendiz de línguas tem necessidade de localização geográfica, de relacionar a língua a um espaço, o trabalho com o tal componente tem como meta levar o aluno a refletir sobre os diferentes contextos sociais, temporais e espaciais.

(1.2) População, grupos sociais e dados históricos. E necessário que haja no componente pluri/intercultural conteúdos que estimulem não só a identificação de grupos, em razão de diferenças sociais, étnicas, profissionais ou outras, mas que se propicie a identificação de distintas perspectivas ou cosmovisões tanto de dentro quanto de fora dos grupos considerados. Neste caso, mostra-se necessário considerar em que medida as atividades propostas estão levando em conta as diferentes perspectivas e olhares sobre diferenças em relação a falantes da(s) língua(s) ou variedades lingüísticas em questão nas aulas.

\footnotetext{
${ }^{2}$ Essa estruturação de três componentes para a constituição de um programa no ensino de línguas foi formulada por Serrani (2005), à luz da proposta de Stern (1993) cujo modelo se apóia em quatro componentes ou sílabos, conforme a terminologia adotada pelo autor.
} 
(1.3) Realizações artísticas, científicas, ecológicas e outros legados culturais. É preciso pensar uma didática de línguas na qual "funcionar em uma língua" seja uma finalidade necessária, mas não suficiente ${ }^{3}$. Neste aspecto, é preciso compreender, no estudo da língua, a dimensão dos legados culturais e da relação identitária, social e emocional com contextos regionais ou nacionais.

(2) Componente de língua/discurso: Assim sendo, o texto deve ser visto não como soma de frases, mas como uma totalidade lingüístico-histórica que não se restringe à dimensão linear do dizer, isto é, aquilo que o enunciador efetivamente formula num momento dado, em relação ao que disse antes e dirá depois. Há também uma outra dimensão, a do interdiscurso, o eixo vertical do dizer, de constituição dos sentidos.

Se há uma rede complexa de formações discursivas em que o texto está sendo inserido, a proposta pretende considerá-la nas práticas de leitura e escrita do texto no que diz respeito ao funcionamento discursivo dos operadores argumentativos, que podem produzir efeitos de contrariedade, adição de idéias, gradação, exemplificação e conclusão na construção do ensaio.

Neste caso, é preciso trabalhar com a dimensão argumentativa no intradiscurso do texto, considerando assim a interdiscursividade daquele. Dito de outro modo, é válido partir do princípio da relação materialidade lingüística-processo discursivo, ou seja, nesta proposta, vale pensar que o sistema da língua só se realiza em processos discursivos de sentido.

Os processos discursivos de sentido dizem respeito a posições ideológicas e à questão do poder e das hierarquias sociais sempre presentes em todo discurso. Assim, na abordagem da língua, à luz da proposta multidimensional, é possível considerar o papel desempenhado, por exemplo, pelas posições enunciativas em diferentes variedades (formal, informal, etc.), pela dimensão argumentativa do texto que está explícita e implícita nas formulações dos textos a serem trabalhados ou pelos elementos da língua e as relações de sentido estabelecidas por meio desses recursos-conjunções, operadores, expressões em termos de efeitos sobre um dado leitor.

(3) Componente de Práticas Verbais: concretização interdependente dos componentes anteriores em práticas de leitura e escrita.

\section{Texto exemplar da abordagem}

\section{O Brasil Jardim do Paraíso- Marilena Chauí}

Diários de bordo e cartas dos navegantes e dos evangelizadores não cessam de referir-se às novas terras falando da formosura de suas praias imensas, da grandeza e variedade de seus arvoredos e animais, da fertilidade de seu solo e da inocência de suas gentes que "não lavram nem criam (...) e andam tais e tão rijos e tão nédios que o não somos nós tanto, com quanto trigo e legumes comemos", como se lê na "Carta de Pero Vaz de Caminha a El Rei Don Manuel Sobre o Achamento do Brasil".

É dessa carta a passagem celebrada: "Águas são muitas; infindas. E em tal maneira graciosa que, querendo-se aproveitar, dar-se-á nela tudo, por bem das águas que tem". Quando se examinam relatos aparentemente descritivos, não se pode deixar de notar que certos lugares-comuns se encontram em todos eles. $\mathrm{O}$

${ }^{3}$ Conferir Serrani (2005, p. 32). 
Brasil é sempre descrito como imenso jardim perfeito: a vegetação é luxuriante e bela (flores e frutos perenes), as feras são dóceis e amigas (em profusão inigualável), a temperatura é sempre amena ("nem muito frio, nem muito quente", repete toda a literatura e Pero Vaz de Caminha), aqui reina a primavera eterna contra o "outono do mundo", o céu está perenemente estrelado, os mares são profundamente verdes, e as gentes vivem em estado de inocência, sem "esconder suas vergonhas" (diz Pero Vaz), sem lei e sem rei, sem crença e pronta para a evangelização.

Esses lugares-comuns literários possuem um sentido preciso que não escaparia a nenhum leitor dos séculos 16 e 17: são os sinais do Paraíso Terrestre reencontrado. Nascido sob o signo do Jardim do Éden, o mito fundador não cessará de repô-lo. Três exemplos podem ajudar-nos a perceber a permanência dessa, muito depois de encerrada a exegese mítica da descoberta-conquista. Praticamente quase todas as bandeiras nacionais, criadas nos vários 18 países durante o século 19 e início do século 20, são bandeiras herdeiras da Revolução Francesa. Por isso são tricolores (algumas poucas são bicolores), as cores narrando acontecimentos sócio-políticos dos quais a bandeira é a expressão.

A bandeira brasileira é a única não-tricolor produzida nesse período. Possui quatro cores. Ora, quando se pergunta qual o significado dessas cores, não se responde que o verde, por exemplo, simbolizaria lutas camponesas pela justiça, mas sim que representa nossas imensas e inigualáveis florestas; o amarelo não simboliza a busca da Cidade do Sol, utopia de Campanella da cidade ideal, mas representa a inesgotável riqueza natural do solo pátrio; o azul não simboliza o fim da monarquia dos Bourbons e Orléans, mas a beleza perene de nosso céu estrelado, onde resplandece a imagem do Cruzeiro, sinal de nossa devoção a Cristo Redentor; e o branco não simboliza a paz conquistada pelo povo, mas a ordem (com progresso, evidentemente).

A bandeira brasileira não exprime a política nem a história. É um símbolo da Natureza: floresta, ouro, céu, estrela e ordem. É o Brasil-jardim, o Brasilparaíso terrestre. O mesmo fenômeno pode ser observado no Hino Nacional, que canta mares mais verdes, céus mais azuis, bosques com mais flores e nossa vida de "mais amores". O gigante está "deitado eternamente em berço esplêndido", isto é, na Natureza como paraíso ou berço do mundo, e é eterno em seu esplendor.

E, terceiro exemplo, a poesia ufanista que toda criança aprende a recitar na escola, como o poema do conde Afonso Celso, "Porque Me Ufano de Meu País", ou os sonetos parnasianos de Olavo Bilac: "Ama com fé e orgulho a terra em que nasceste!/ Criança, jamais verás país como este!/ Olha que céu, que mar que floresta!/ A natureza, aqui perpetuamente em festa,/ É um seio de mãe a transbordar carinhos". Essa produção mítica do país-paraíso nos persuade de que nossa identidade e grandeza se encontram predeterminadas no plano natural: somos sensíveis e sensuais, carinhosos e acolhedores, alegres e sobretudo somos essencialmente não-violentos. O primeiro elemento da construção mítica nos lança e conserva no reino da Natureza, deixando-nos fora do mundo da História.

\section{Uma abordagem discursiva da textualidade: língua e cultura}

Especificamente, tendo-se em vista o texto (ensaio) de autoria de Marilena Chauí, busquei seguir um roteiro de questões propostas por Serrani (2005, p. 31): Quais territórios e contextos históricos estão considerados nos conteúdos do curso/disciplina? Eles permitem trabalhar a diversidade sociocultural e quais gêneros discursivos em 
foco? Com base nessas interrogações e apoiada no texto acima, elaborei o seguinte planejamento, voltado para uma turma de terceiro ano do curso de Letras:

\section{Componente intercultural}

a) territórios, espaços e momentos: com a leitura do texto de Marilena Chaú, proponho um trabalho a respeito das diferentes identidades culturais do Brasil: Comparação entre a região semi-árida do Brasil e de seu litoral a partir de filmes nacionais (Abril despedaçado) e internacionais que abordam o Brasil (Turistas).

b) pessoa e grupos sociais: a oposição entre grupos que "buscam” um Brasil paraíso e aqueles que vivem a realidade do Brasil sertão.

c) legados socioculturais: trabalho com um filme nacional que aborda a realidade do sertão brasileiro (Abril despedaçado) e um filme estrangeiro (Turistas), filmado no litoral brasileiro, no qual o país é representado como elemento exótico.

\section{Componente de língua-discurso}

a) materialidade lingüística: um exame das construções sintáticas e o funcionamento dos operadores discursivos, partindo de uma visão em que a própria materialidade lingüística do texto esteja atrelada à sua historicidade (mas cabe mencionar aqui que não estamos focando a aula na questão da categoria gramatical, pois nossa tendência teórica é de perspectiva discursiva).

b) gênero discursivo: ensaio; obras cinematográficas.

\section{Componente de práticas verbais: oficinas de leitura e escrita de ensaios críticos}

Iniciando pelo componente intercultural, houve a necessidade de trabalhar com um debate, a partir das obras cinematográficas, para propiciar a escrita de um ensaio em que os alunos abordassem a problemática do conflito social brasileiro, tendo como ponto de partida a heterogeneidade nacional: o abismo existente entre os contextos paradisíacos e aqueles calcados na dor e na falta de estrutura. Destaca-se, aqui, a relevância da obra cinematográfica como possibilidade de abordagem das relações intersemióticas (discutir a convivência entre a linguagem verbal e visual) nos filmes, permitindo ao aluno refletir sobre outras formas de linguagem.

Em termos de produção escrita, a temática "cultural” dos filmes serve como ponto nodal para a escrita de ensaios críticos. Assim, é interessante considerar, em Abril despedaçado, a relevância da análise do contexto no qual o drama ocorre (um lugarejo onde moram as famílias Breves e Ferreira, lugar em que o antigo riacho secou) e o enredo da obra que narra a saga de duas famílias rivais que lutam entre si a fim de garantir a honra. Neste caso, a vingança representa a única lei que permanece naquela região, única certeza nas vidas tristes e miseráveis daqueles que vivem desiludidos, pobres e num contexto marcado por desamparo e dor.

Em se tratando do filme Turistas, esse conta a saga de jovens estrangeiros que vêm ao Brasil a fim de encontrar belezas naturais, diversão e muita praia e que acabam dominados por uma quadrilha de traficantes de órgãos. Mas, além da tentativa de mostrar belas praias e um clima de grande descontração no país, há no filme a recuperação de lugares-comuns que colocam o país como lugar selvagem, de muita libertinagem e sexualidade exacerbada. 
Neste sentido, em consonância com Serrani (2005, p. 32) entendemos que "os legados culturais e os domínios identitários, social e emocional do sujeito estão relacionados”. Portanto, conteúdos ou atividades relacionadas a tais domínios facilitam a mobilização do sujeito em relação à aprendizagem.

Considerando-se as práticas verbais em conexão com o componente línguadiscurso, sem perder de vista a temática cultural, conduzi uma prática de leitura do ensaio de Chauí no qual o texto fosse visto não como um objeto fechado em si mesmo, mas como parte de um processo discursivo mais amplo. Analisar a textualidade do ensaio, um texto crítico e reflexivo, nos leva a pensar que a memória sobre o Brasil ganha corpo no dizer, isto é, podemos compreender de que maneira os sentidos sobre a brasilidade vão se constituindo nos percursos de nossa história.

Neste caso, apresento meu planejamento de aula, considerando, também, a relevância da leitura em língua materna. Apoiando-me nas análises pré-pedagógicas de Baghin-Spinelli (2002) e Serrani (2000), aponto um caminho possível de abordagem discursiva da textualidade do ensaio de Chauí. Num primeiro momento, voltei meu olhar para a direção argumentativa do texto, ou seja, para as construções sintáticas que emergem na formulação do ensaio.

\section{Hierarquização das dependências funcionais (direção argumentativa)}

Vale trazer à tona a esquematização de um parágrafo do texto, quando se percebem dominâncias enunciativas em expansão, isto é, a presença de um enunciado dominando outros que sustentam o argumento do primeiro.

Três exemplos podem ajudar-nos a perceber a permanência dessa, muito depois de encerrada a exegese mítica da descoberta-conquista

\begin{tabular}{|c|c|c|}
\hline$\downarrow$ & \multirow{3}{*}{$\begin{array}{l}\text { no Hino Nacional, que } \\
\text { canta mares mais } \\
\text { verdes, céus mais azuis, } \\
\text { bosques com mais flores } \\
\text { e nossa vida de "mais } \\
\text { amores". O gigante está } \\
\text { "deitado eternamente em } \\
\text { berço esplêndido", isto } \\
\text { é, na Natureza como } \\
\text { paraíso ou berço do } \\
\text { mundo, e é eterno em } \\
\text { seu esplendor. }\end{array}$} & \multirow{3}{*}{$\begin{array}{l}\text { E, terceiro exemplo, a } \\
\text { poesia ufanista que toda } \\
\text { criança aprende a recitar } \\
\text { na escola, como o poema } \\
\text { do conde Afonso Celso, } \\
\text { "Porque Me Ufano de } \\
\text { Meu País", ou os sonetos } \\
\text { parnasianos de Olavo } \\
\text { Bilac: "Ama com fé e } \\
\text { orgulho a terra em que } \\
\text { nasceste!/ Criança, jamais } \\
\text { verás país como este!/ } \\
\text { Olha que céu, que mar que } \\
\text { floresta!/ A natureza, aqui } \\
\text { perpetuamente em festa,/ } \\
\text { É um seio de mãe a } \\
\text { transbordar carinhos". }\end{array}$} \\
\hline $\begin{array}{l}\text { A bandeira brasileira } \\
\text { não exprime a política } \\
\text { nem a história. É um } \\
\text { símbolo da Natureza: } \\
\text { floresta, ouro, céu, } \\
\text { estrela e ordem. É o } \\
\text { Brasil-jardim, o Brasil- } \\
\text { paraíso terrestre. }\end{array}$ & & \\
\hline & & \\
\hline
\end{tabular}


Cynthia, aumentei um pouco a largura da $1^{\text {a }}$ coluna, à esquerda, para ficar com menos espaço entre as palavras.

Em relação aos argumentos em expansão, podemos destacar a repetição de itens lexicais e expressões sintáticas que participam da construção de uma representação dominante de Brasil-paraíso: floresta, ouro, céu, Brasil-jardim, mares mais verdes, céus mais azuis, bosques com mais flores, natureza aqui perpetuamente em festa constitutiva de nosso imaginário e inaugurada com a carta de Caminha. Essas construções reiteram sentidos ligados a um mito de um paraíso redescoberto, no contexto de produção de documentos de descrição do Brasil e estão relacionados a um gesto da nossa história que foi nos constituindo até os dias de hoje: seja no Hino Nacional, seja na bandeira, seja no discurso escolar.

Com efeito, é preciso no trabalho com o ensaio considerar as tensões presentes em nossa sociedade. Um imaginário discursivo calcado numa imagem de paraíso funciona no sentido de apagar os conflitos nacionais e de silenciar os espaços em que a referência não seja a de paraíso.

Dessa forma, na medida em que o ensaio de Chauí faz retornar uma memória, um discurso que está ancorado em um mito fundador da brasilidade para colocá-lo em suspenso, é preciso não perder de vista toda a riqueza da discussão sobre a identidade brasileira, em termos de conflitos. Para Orlandi (2003, p. 7), numa visão discursiva, a Carta de Caminha é um discurso fundador, ou seja, aquele que funciona como referência básica no imaginário constitutivo do país, estabilizando-se, assim, como referência na construção da memória nacional. De fato, é possível pensar em interrogações de ordem discursiva, a partir da leitura do ensaio: qual a relação dessa representação de paraíso com o país? E de que maneira, esse lugar-comum retorna?

\section{Funcionamento textual das construções sintáticas:}

a) Construções predominantes: no ensaio, há predominância de período simples (afirmações de aparência categórica);

b) Análise da seleção lexical:

E (1): Quando se examinam relatos aparentemente descritivos, não se pode deixar de notar que certos lugares-comuns se encontram em todos eles.

O ensaio aponta para uma posição de crítica em relação aos documentos históricos (cartas ou relatos) sobre o Brasil. O movimento de levar textos polêmicos e de cunho crítico sobre questões culturais precisa constituir os espaços da sala de aula, de modo que o aluno, futuro professor, compreenda os sentidos estabilizados e a possibilidade de o sentido ser diferente, produzindo o novo.

No ensaio de Chaúí, o que há é a mobilização de uma memória nacional, fundamentada no trabalho de interpretação sobre a historicidade do dizer (ORLANDI, 1998). A forma adverbial aparentemente, que irrompe o nível da formulação, coloca em cena sentidos de que os relatos não somente descrevem, como também interpretam a realidade brasileira, atribuindo ao Brasil imagens fixas e fechadas em si mesmas. Tais discursos funcionam como fundadores de um mito de Brasil paraíso, tomado pela ensaísta como construção mítica, o que pode ser notado no uso da expressão "lugares comuns".

\section{E (2): O Brasil é sempre descrito como imenso jardim perfeito}


O uso da forma adverbial sempre aponta para uma insistência da ensaísta em promover a crítica e manter a orientação argumentativa de seu texto: no caso do Brasil, a descrição sobre tal objeto é recorrente, em meio a uma imagem de jardim perfeito que se repete e se atualiza nos discursos sobre ser brasileiro.

Tratando da questão dos operadores discursivos e da necessidade de argumentar sobre um tema polêmico e instigante, considero que, no meio acadêmico, é preciso enfocar um trabalho com o estabelecimento de relações de sentido entre idéias do texto, levando em consideração efeitos de sentidos produzidos, em meio a um processo em que o aluno-professor reflita sobre a relação do sentido com as condições de produção do texto.

Mas se levarmos em conta que essas palavras funcionam, temos que, nos termos de Orlandi (2001, p. 125), considerar o texto como "uma atividade estruturante de um discurso determinado, por um falante determinado, para um locutor determinado, com finalidades específicas”. Ou seja, o ensaio de Chauí é um texto que projeta a imagem de um leitor para o qual é relevante produzir a crítica sobre o Brasil. Também, a autora fala de um lugar legitimado que autoriza seu dizer e produz um discurso que segue uma direção argumentativa que tende a romper com os estereótipos culturais.

Ao considerarmos o texto não como uma seqüência fechada sobre ela mesma, é necessário referi-lo ao conjunto de discursos possíveis a partir de um estado definido de condições de produção, que representam o mecanismo de situar os protagonistas e o objeto do discurso. Neste caso, as condições de produção do ensaio estão relacionadas ao papel dos intelectuais de produzirem um espaço de reflexões em torno do país e de seus problemas.

c) Papel dos operadores argumentativos:

(E3) Ora, quando se pergunta qual o significado dessas cores, não se responde que o verde, por exemplo, simbolizaria lutas camponesas pela justiça, mas sim que representa nossas imensas e inigualáveis florestas; o amarelo não simboliza a busca da Cidade do Sol, utopia de Campanella da cidade ideal, mas representa a inesgotável riqueza natural do solo pátrio; o azul não simboliza o fim da monarquia dos Bourbons e Orléans, mas a beleza perene de nosso céu estrelado, onde resplandece a imagem do Cruzeiro, sinal de nossa devoção a Cristo Redentor.

(E4) Essa produção mítica do país-paraíso nos persuade de que nossa identidade e grandeza se encontram predeterminadas no plano natural: somos sensíveis $e$ sensuais, carinhosos $e$ acolhedores, alegres $e$ sobretudo somos essencialmente não-violentos.

Se o texto de Marilena Chauí problematiza o mito fundador que coloca o brasileiro como fazendo parte da natureza, temos um jogo entre o operador que exprime tempo (conjunção temporal quando) e a conjunção adversativa mas, marcando uma forte oposição no texto. Os sentidos esperados em relação ao Brasil produzem a contrariedade e a quebra de expectativa: o verde não simboliza a justiça, mas sim nossas matas.

Também, o uso da conjunção aditiva $e$ participa de uma soma de argumentos (características) que apontam para uma mesma direção argumentativa: a de que o Brasil, assim como a natureza, traz em si naturalidade, leveza e grandeza, representação que se contrapõe a uma identidade histórica. 
Em sintonia com Orlandi (1993) algumas dessas idéias e dizeres sobre ser brasileiro nos parecem naturais, quando, na realidade, são formadas em um processo histórico. Os sentidos ligados ao sentimento de brasilidade, à imagem da terra pródiga, gigante acabam caindo da ideologia do pouco esforço e do desperdício (já que a terra é boa, não exige esforços por parte de seu povo). Neste caso, o povo brasileiro, muitas vezes, é construído como sensual e desligado da cultura, na medida em que ele incorpora a natureza à sua identidade.

\section{Trabalhando a intertextualidade}

Em relação ao componente intercultural, primeiramente, é relevante trabalhar a relação do ensaio de Chaú com outros discursos. No que concerne à intertexutalidade, neste caso, podem-se ressaltar marcas do discurso- outro que participam da produção de sentidos sobre o Brasil, mobilizando um espaço de memórias.

Percebemos a presença do discurso da Carta de Caminha que é citado diretamente (heterogeneidade mostrada) no fio do dizer para uma reinterpretação de nossa historicidade de brasileiros. Se a Carta constrói o Brasil como Jardim-paraíso, mostra-se necessário, no debate sobre o texto, trabalhar com as formas de permanência deste mito na sociedade e na nossa identidade.

Em seguida, há referências ao Hino Nacional, o que está intimamente atrelado à constituição da bandeira e de suas cores representativas. Novamente, os mitos da natureza prodigiosa e de nossa paz são problematizados pela ensaísta, o que também pode levar o professor a questionar este estereótipo de Brasil-maravilha que retorna em imagens da mídia, na propaganda turística, no discurso de estrangeiros que buscam aqui um lugar de liberação e de contato com a natureza e o exótico.

Por fim, há a referência aos poemas de Afonso Celso e Olavo Bilac. São textos trazidos à cena aos quais a autora se contrapõe para construir sentidos sobre ser brasileiro: mitos ligados à nossa grandeza, a exaltação à beleza, à abundância, à sensualidade brasileira. Neste aspecto, é relevante pensar, em termos culturais, que papel a natureza desempenha na produção identitária nacional?

Neste sentido, é preciso estabelecer diálogos entre o ensaio e os filmes. Se de um lado, o sertão parece esfacelar essa representação de país paraíso, de águas infindas, outros filmes ainda vão colocar o brasileiro mesclado de modo estreito à natureza a ponto de que ela mesma se encarrega de constituir sua identidade. Justamente essa tensão de sentidos e de "verdades" que podem servir de pano de fundo para a produção de ensaios críticos, conforme um gesto no qual os alunos possam articular línguadiscurso e cultura. Nas palavras de Baghin-Spinelli (2002, p. 96): “a materialidade lingüística pode (e deve) ser trabalhada nas nossas salas de aulas, mas nunca com o fim dela mesma, sem a consideração do processo discursivo do qual ela faz parte”.

\section{Uma parada}

Cabe lembrar que as atividades sugeridas com o ensaio e com os filmes (tomados como exemplos de legados culturais) funcionam apenas como ilustrações que reforçam uma busca por "caminhos para uma educação em línguas não instrumentalista, com currículos estruturados em mais de uma dimensão e que dêem prioridade a uma visão não compartimentalizada de língua, discurso, literatura e memória” (SERRANI, 2007, p. 69). 
Certamente, as atividades sugeridas são algumas dentre outras que poderiam também ter sido pensadas, no caso do texto aqui contemplado. Neste caso, a ilustração teve como objetivo mostrar as possibilidades de articulação entre conteúdos socioculturais, com práticas verbais, à luz de uma visão de texto tomado em suas dimensões lingüísticas e históricas.

Com efeito, procurei defender a imbricação da língua com a memória sociocultural no ensino de Língua Portuguesa, por meio da utilização de textos que abordem temáticas culturais, em práticas letradas, não somente com o pretexto de trabalhar a língua, mas pensar contextos culturais/sociais diversos, os cenários e modos de vida que representam a brasilidade. Vale lembrar que, nas palavras de Serrani (2005, p. 15), o profissional de língua deve estar "apto para realizar práticas de mediação sócio-cultural,

contemplando o tratamento de conflitos identitários e contradições sociais, na linguagem da sala de aula”.

Assim, ao mesmo tempo em que procurei explorar a dimensão lingüística nas atividades, também me esforcei para ressaltar a questão intercultural, em um planejamento em que a heterogeneidade da linguagem, da nossa sociedade e da identidade nacional são elementos basilares.

Enfim, meu estudo dialoga com a tendência de não dicotomizar língua e literatura, língua e cultura, identidade e linguagem. Tento avançar nos estudos discursivos, pensando, neste caso, o gênero ensaio, propondo, para tanto, algumas reflexões em torno da idéia do texto como lugar de articulação do lingüístico e o histórico (o domínio das memórias) ou ainda entender a construção do discurso sobre o Brasil como um jogo de vozes discordantes, configurações de posições distintas, várias perspectivas e modos de conceber as coisas. Um território complexo.

\section{Referências}

BAGHIN-SPINELLI, Débora. Uma proposta discursiva de leitura nos cursos de formação de professores de língua inglesa. In: SERRANI, Silvana. (Org.). Fragmentos. Florianópolis: Ed. da UFSC, 2002, p. 79-100.

CHAUÍ Marilena. O mito fundador do Brasil. Caderno Mais. Suplemento, São Paulo, 26/03/2000.

ORLANDI, Eni. Discurso fundador: a formação do país e a construção da identidade nacional. Campinas: Pontes, 1993.

Discurso e leitura. São Paulo: Cortez, Campinas: Editora da Unicamp, 1993.

Identidade lingüística escolar. In: SIGNORINI, Inês (Org.). Lingua(gem) $e$ identidade: elementos para uma discussão no campo aplicado. Campinas: Mercado de Letras, 1998. p. 203-212.

Análise de discurso: princípios e procedimentos. Campinas: Pontes, 1999.

2001.

Discurso e texto: formulação e circulação dos sentidos. Campinas: Pontes, 
PÊCHEUX, Michel (1975). Semântica e discurso: uma crítica à afirmação do óbvio. Campinas: Editora da UNICAMP, 1988.

SERRANI, Silvana. Discurso sobre língua, textualidade e línguas estrangeiras próximas. In: Anais da Anpoll, Niterói, Rio de Janeiro, 2000.

Discurso e cultura na aula de língua - currículo, leitura e escrita. Campinas: Pontes, 2005.

Legados literário-culturais, memória e antologias na educação em línguas (currículo de espanhol no Brasil). In: KLEIMAN, Angela; CAVALCANTI, Marilda (Orgs.). Lingüística Aplicada - suas faces e interfaces. 1. ed. Campinas: Mercado de Letras, 2007. p. 55-71.

STERN, Hans Heinrich. Issues and options in language teaching. Oxford: Oxford University Press, 1993. 